\title{
Quantitative Anatomic Comparison of the Extended Pterional Transtemporal Transtentorial Approach and the Subtemporal Transtentorial Approach to the Petroclival Region
}

\author{
Petroklival Bölgeye Genişletilmiş Pterional Transtemporal Transtentorial \\ Yaklaşım ve Subtemporal Transtentorial Yaklaşımın Kantitatif Anatomik \\ Karşılaştırması
}

Yong TANG ${ }^{1}$, Han-Dong WANG ${ }^{1}$, Chi-Yuan MA ${ }^{1}$, Chao-Shuang ZHAN ${ }^{2}$, Xiang-Jun JI ${ }^{1}$, Lin ZHU ${ }^{1}$, Wei $\mathrm{LI}^{1}$, Wan-Chun YOU ${ }^{1}$, Hai-Ping LIN $^{3}$, Wu-Zhao ZHONG ${ }^{3}$

${ }^{1}$ Nanjing University, School of Medicine, Jinling Hospital, Department of Neurosurgery, Nanjing, China

${ }^{2}$ Nanjing University, School of Medicine, Department of Anatomy, Nanjing, China

${ }^{3}$ Southern Medical University (Guangzhou), School of Medicine, Jinling Hospital, Department of Neurosurgery, Nanjing, China

Corresponding Author: Han-Dong WANG / E-mail: hdwang61@yahoo.com.cn

\begin{abstract}
AIM:The anatomic characters and applicability of the extended pterional transtemporal transtentorial (EPTT) approach versus the subtemporal transtentorial (ST) approach for surgical treatment of petroclival tumors were evaluated.

MATERIAL and METHODS: Ten sides from five adult Chinese injected cadavers were manipulated using both two approaches. Four deep bony anatomic landmarks were specified in the skull base to create two adjoining triangles that were respectively located in the anterior and posterior petroclival region. The real, projected area and the percentage of the projected area were determined and calculated to compare the deep exposure from the two approaches.

RESULTS: There was no difference regarding the percentage of the projected area was calculated in the anterior triangles (EPTT, $21.5 \pm 12.5 \%$; ST, $28.8 \pm 14.9 \% ; \mathrm{p}=0.1948$ ), but a significant difference was present in the posterior triangles (EPTT, $74.0 \pm 4.5 \% ; \mathrm{ST}, 51.5 \pm 4.3 \% ; \mathrm{p}<0.01$ ). Compared with the ST approach, the EPTT approach provides an equivalent percentage of projected area in the middle cranial fossa and a wider exposed area in the posterior cranial fossa.

CONCLUSION: Through anatomic comparative analysis the EPTT approach provides better exposure and is more appropriate than the ST approach for large and giant petroclival tumors predominantly in the posterior cranial fossa with extensive invasion to parasellar structures and the cavernous sinus.
\end{abstract}

KEYWORDS: Anatomic study, Petroclival region, Pterional approach, Subtemporal approach, Skull base

öz

AMAÇ: Petroklival tümörlerin cerrahi tedavisi için genişletilmiş pterional transtemporal transtentorial (EPTT) yaklaşımı ile subtemporal transtentorial (ST) yaklaşımının anatomik özellikleri ve uygulanabilirliği karşılaştırmalı olarak değerlendirildi.

YÖNTEM ve GEREÇLER: Her iki yaklaşım kullanılarak beş yetişkin Çinli kadavra çift taraflı olarak açıldı ve incelendi. Kafa tabanında sırasıyla anterior ve posterior petroklival bölgede bulunan yan yana iki üçgen oluşturmak üzere dört adet derin kemik anatomik referans noktası belirlendi. İki yaklaşımın sağladığı derin ekspojuru karşılaştırmak üzere gerçek, projeksiyon yapılmış alan ve projeksiyon yapılmış alanın yüzdesi belirlendi ve hesaplandı.

BULGULAR: Ön üçgenler için hesaplanan projeksiyon alanı yüzdesinde bir fark görülmedi (EPTT, \%21,5 $\pm 12,5 ; \mathrm{ST}, \% 28,8 \pm 14,9 ; \mathrm{p}=0,1948$ ) ama

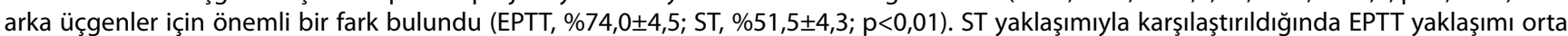
kraniyal fossada eşdeğer projeksiyon yapılmış alan yüzdesi ve posterior kraniyal fossada daha büyük bir açığa çıkarılmış alan sağladı.

SONUÇ: Karşılaştırmalı analiz yoluyla EPTT yaklaşımının temel olarak posterior kraniyal fossada bulunan ve parasellar yapılar ve kavernöz sinüse yaygın invazyon yapmış büyük ve dev petroklival tümörler için ST yaklaşımına göre daha fazla görüş alanı sağladığı ve daha uygun olduğu ortaya çıktı.

ANAHTAR SÖZCÜKLER: Anatomik çalışma, Petroklival bölge, Pterional yaklaşım, Subtemporal yaklaşım, Kafa tabanı 


\section{INTRODUCTION}

Anatomically, the petroclival region is composed of the sphenoid bone, temporal bone and occipital bone. This region bestrides into both middle and posterior cranial fossa (11). The tumors in the petroclival region are always benign and slowgrowing. Therefore, when patients with petroclival tumors have clinical symptoms and go to see a doctor, the tumors have already grown to a large or giant volume and usually extend anteriorly from the dorsum sellae to the parasellar region and cavernous sinus, and posteriorly from the ventral brainstem to the lower clivus and foramen magnum (25) (3). The III XII cranial nerves, basilar artery (BA) and its important branches such as the posterior cerebral artery (PCA) and superior cerebellar artery (SCA), and the petrous segment of the internal carotid artery (ICA) all go through this region.

Gaining access to the petroclival region is a severe challenge for neurosurgeons (5). Deep location in the skull base and the neighboring ventral brainstem make this region very dangerous. When neurosurgeons try to remove petroclival tumors as completely as possible, it is possible to cause neurological deficits and major vascular injury (10). Nonetheless, surgical removal was still considered as the best and most effective selection to manipulate petroclival tumors. Although various approaches to the petproclival region have been described in the literature, the intraoperative exposure and postoperative complication rates were still unsatisfactory (2).

The pterional approach was first created by Yasargil in the 1970s. Previously, it was used to treat aneurysms in the anterior circle of Willis and lesions in the cavernous sinus (16, 31). Gradually, this approach has become one of the classic approaches to the skull base, and it has many advantages such as simple craniotomy, easy surgical technique to learn, clearly visible anatomic structures and short duration. However, due to the occlusion of the temporal lobe, tentorium and petrous bone, the pterional approach did not expose posterior cranial fossa sufficiently (24). We therefore modified the pterional approach, which was named the extended pterional transtemporal transtentorial (EPTT) approach, to improve the exposure of the posterior cranial fossa. In order to quantify the advantages and disadvantages of the EPTT approach, we used the subtemporal transtentorial (ST) approach for comparison.

\section{MATERIAL and METHODS}

\section{Specimen Sources and Surgical Instruments}

The study included 5 adult Chinese cadaveric heads (10 sides) provided by the Department of Anatomy, Nanjing University. Before the surgical approaches were performed, the heads were injected $10 \%$ formaldehyde. Subjects with cranial diseases and traumatic brain injury were excluded. The surgical operations were approved by the ethical committee of Jinling Hospital, Nanjing University.
Surgical instruments included a Leica operating microscope, a Phillips 64-slice CT scanner, a domestic headholder, a set of craniotomy and microsurgical instruments, a ruler (accuracy $1 \mathrm{~mm}$ ), a compass, a vernier caliper (accuracy $0.2 \mathrm{~mm}$ ), and a digital camera.

\section{Surgical Preparations and Procedures}

Before the surgical approaches, bilateral carotid arteries, jugular veins and vertebral arteries in 5 cadaveric heads were perfused with red and blue color latex respectively. These cadaveric heads were then placed in the refrigerator at $-20^{\circ}$ for about one week to mix the color latex sufficiently.

Five cadaveric heads were dissected bilaterally by both the EPTT and ST approach. The heads were fixed with headholder rigidly. The ST approach was performed at first to prevent the distortion of anterior temporal lobe caused by the EPTT approach. While the EPTT and ST approaches were performed, the compass and vernier caliper were used to measure the correlative structural length and distance.

\section{MEASUREMENT TECHNIQUES}

\section{Deep Anatomic Points}

We selected 4 deep points in the skull base. The anterior point (Point A) was defined as the apex of the anterior clinoid process. The medial point (Point $M$ ) was the midpoint of the dorsum sellae. The lateral point (Point $\mathrm{L}$ ) was defined as the apogee of the arcuate eminence. The posterior point (Point P) was defined as the midline of the clivus to the level of the homolateral internal auditory foramen (13). These 4 deep points formed two adjoining triangles. The anterior triangle $A M L$, created by Point $A, M$, and $L$, occupied the part of the middle cranial fossa in a relatively horizontal plane. The posterior triangle $\mathrm{PML}$, created by Point $\mathrm{M}, \mathrm{L}$, and $\mathrm{P}$, occupied the part of the posterior cranial fossa in an inclined plane and was not in the same plane as the anterior triangle.

\section{External Bony Landmarks}

In an external bone window, 3 points were defined to establish the bone window plane in each approach as follows: for the EPTT approach, Ex-K, the keyhole; Ex-F, the point in frontal bone and $3 \mathrm{~cm}$ upper to supraorbital margin $3 \mathrm{~cm}$ from midline); Ex-S, the point in squamous suture and $6 \mathrm{~cm}$ upper to external auditory foramen. Similarly, for the ST approach, in addition to Ex-S, another 2 external points were selected: Ex$C$, the supramastoid crest; Ex-Z, the midpoint of the superior margin of the zygomatic arch.

\section{Data Collection and Calculation}

The Phillips 64-slice CT scanning was used at first to scan the five specimens with a slice thickness at $0.75 \mathrm{~mm}$. Then we established a spatial rectangular coordinate system $(17,22)$. Point $O$ was defined as the origin. The $X, Y$, and $Z$ axes were defined respectively as perpendicular to the sagittal plane, coronal plane and axial plane (Figure 1). The CT images were used to record the before-mentioned 4 deep and 5 external points with the computer software named Adobe 


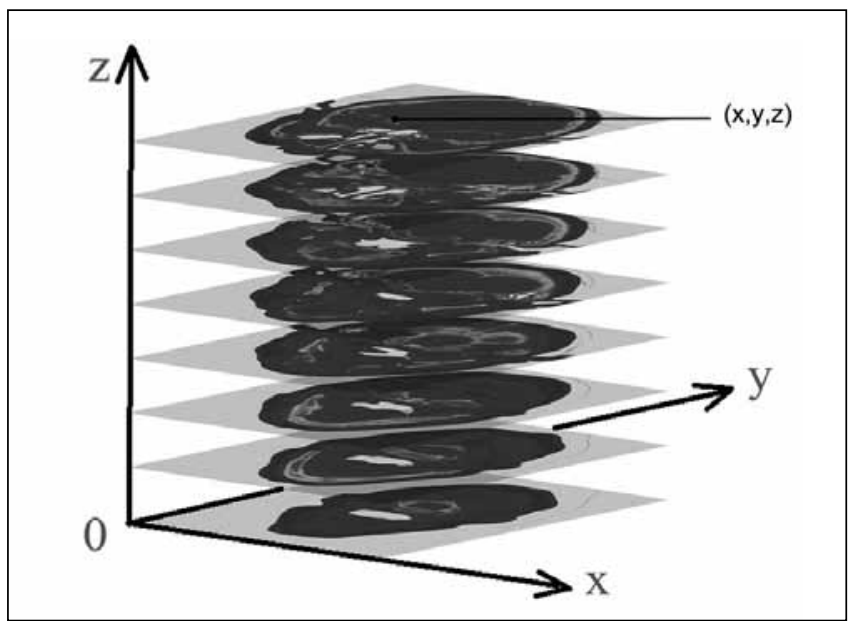

Figure 1: The schematic diagram of construction of threedimensional coordinate system model. Point $O$ was defined as origin. The $X, Y$, and $Z$ axes were defined as respectively perpendicular to the sagittal plane, coronal plane and axial plane. The random anatomic points are represented as $(x, y, z)$.

photoshop CS5. The results were only planar $(x, y)$. According to the point located in a slice, the value of the $Z$ axis could be calculated combined with slice thickness. Then another computer software named Microsoft visual $\mathrm{C}++6.0$ was used to carry out programming based on the correlative principle of spatial analytic geometry. The program was run correctly with verification. This could eliminate the need for using a navigation system before and after the specimens were approached.

The calculations were performed for 3 types of measurements. First, the real area, defined as the real calculated area of the triangle formed by the deep coordinate points and representing the real anatomic area was determined. Second, the projected area, defined by each approach and representing the projected area of the deep triangle on the bone window plane of each surgical procedure was measured. Last, the percentage of the projected area was defined as the projected area converted to a percentage by comparing it with the real area. This transformation effectively reduced the variation in real area for each cadaveric head.

\section{Statistical Analysis}

Paired $t$ tests were performed with the statistical software SPSS 17.0. All data were presented as mean \pm standard deviation. A $p$ value less than 0.05 was considered to be statistically significant.

\section{RESULTS}

\section{Surgical Procedures of ST and EPTT Approaches}

The subtemproal transtentorial (ST) approach was well known by neurosurgeons, the craniotomy and microscopic vision (Figure 2A-D) was no need to repeat. In the extended pterional transtemporal transtentorial (EPTT) approach (Figure 3A-D), procedures using the supine position and

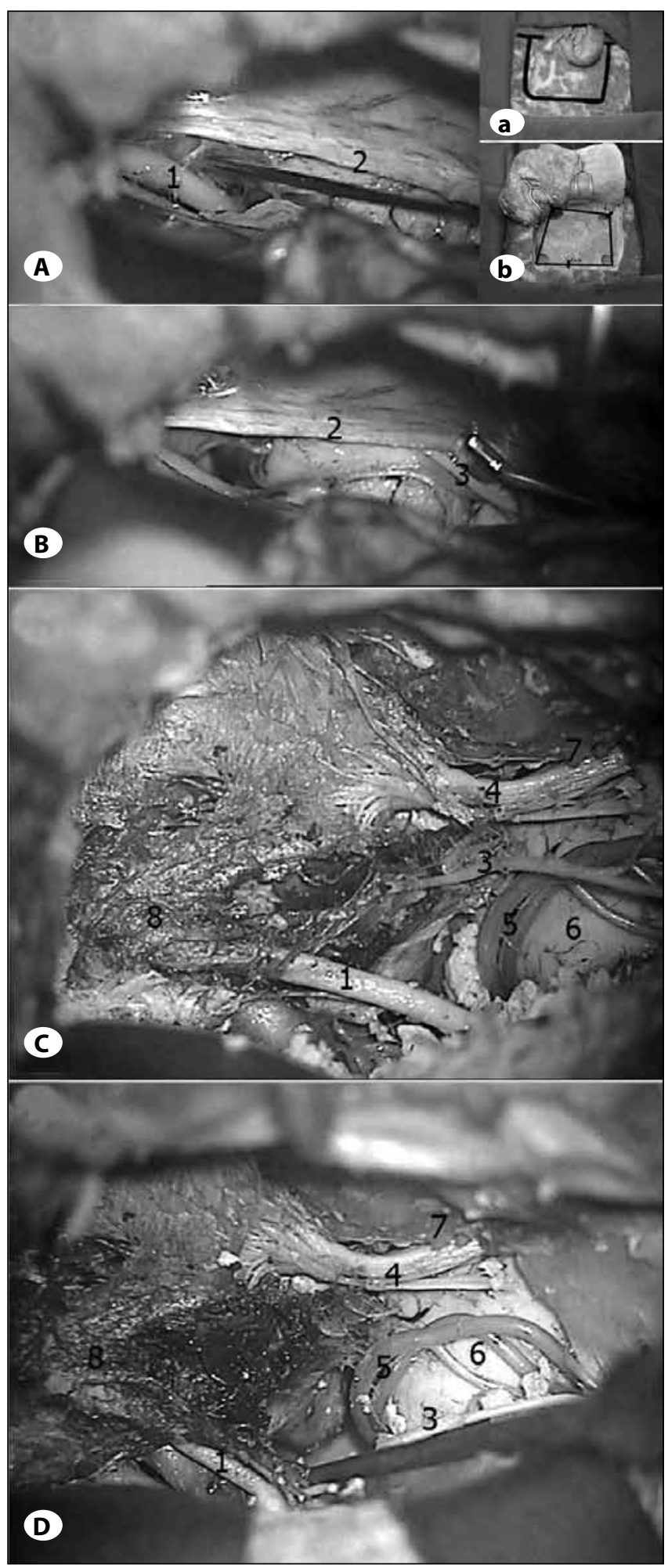

Figure 2: The craniotomy and microscopic appearance of the ST approach (the right side). a) The skin incision of the ST approach. b) The 4 bone holes and bone window in the ST approach. A-D) Anatomic appearance of the ST approach under the microscope. 1, Oculomotor nerve; 2, Free margin of the tentorium; 3, Trochlear nerve; 4, Trigeminal nerve; $\mathbf{5}$,Superior cerebellar artery (SCA); 6, Brainstem; 7, Petrous bone; 8, Cavernous sinus. 

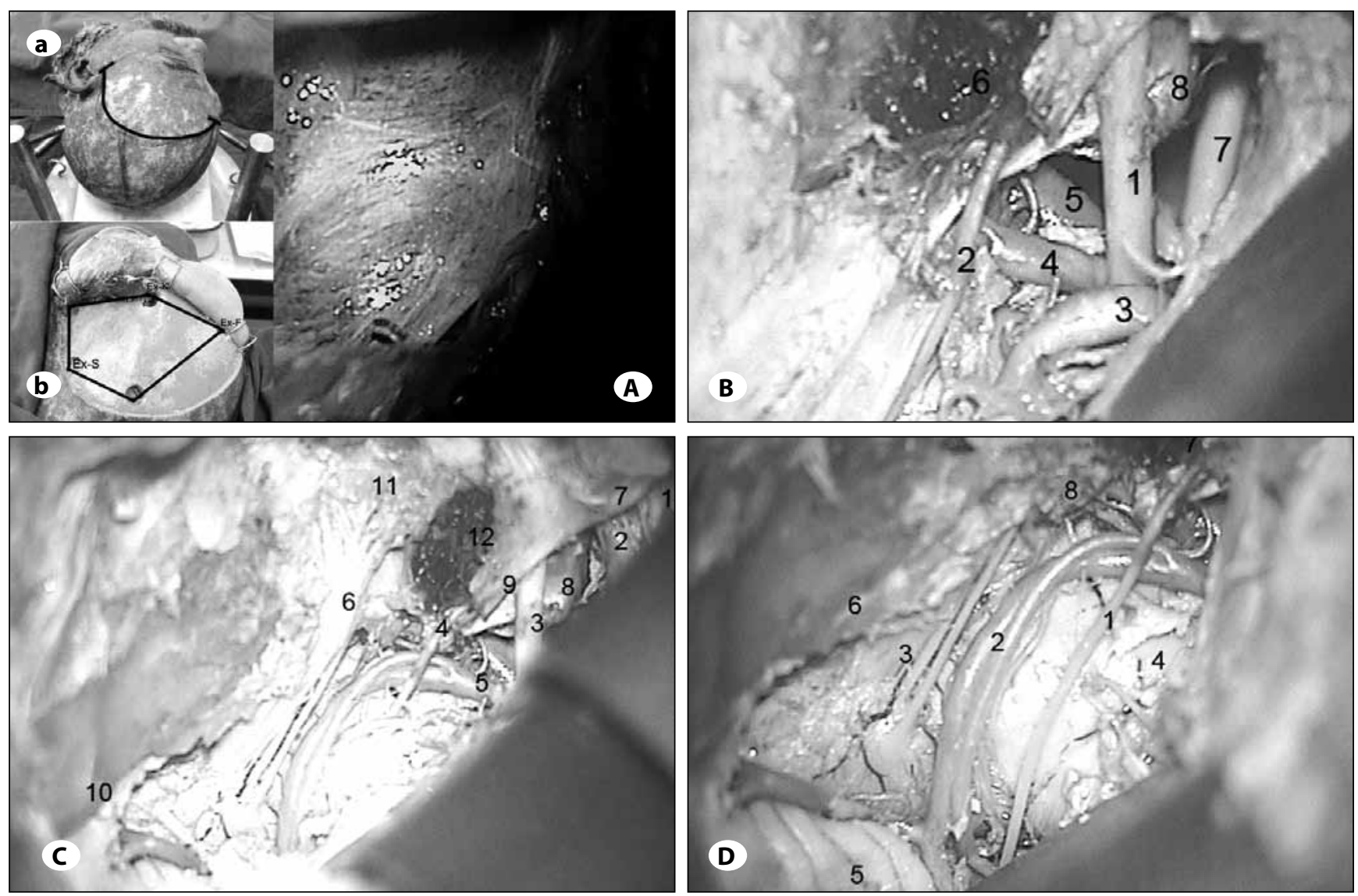

Figure 3: The craniotomy and microscopic appearance of the EPTT approach (the left side). a) The skin incision of the EPTT approach. b) The 5 bone holes and bone window in the EPTT approach. A) Retract the temporal lobe and expose the free margin of the tentorium. B) Expose the middle cranial fossa: 1, Oculomotor nerve; 2, Trochlear nerve; 3, Superior cerebellar artery (SCA); 4, Posterior cerebral artery (PCA); 5, Basilar artery (BA); 6, Cavernous sinus; 7, Contralateral Oculomotor nerve; 8, posterior clinoid process. C) Expose the whole area of EPTT approach: 1, optic nerve; 2, internal carotid artery (ICA); 3, Oculomotor nerve; 4, Trochlear nerve; 5, Superior cerebellar artery $(\mathrm{SCA}) ; \mathbf{6}$, trigeminal nerve; $\mathbf{7}$, anterior clinoid process; $\mathbf{8}$, posterior clinoid process; $\mathbf{9}$, free margin of the tentorium. 10, the apex of the arcuate eminence; 11, trigeminal gasserian ganglion; 12, Cavernous sinus; D) Expose the posterior cranial fossa: 1, Trochlear nerve; 2, Superior cerebellar artery (SCA); 3, The beginning of trigeminal nerve; 4, brainstem; 5, cerebellar hemisphere; $\mathbf{6}$, Petrous bone; $\mathbf{7}$, Cavernous sinus; $\mathbf{8}$, free margin of the tentorium.

with cadaveric head lateral oblique to nonoperative side maintained about $60^{\circ}$ rotations. The skin incision was opened in an arcuate shape extending from the superior margin of the zygomatic arch to the frontal hairline of midline with a moderate enlargement posterior to the temporal region. When the skin flap and temporal muscle were turned over downward to the keyhole above the eye brow, five bone holes were drilled, the bone holes were connected with wire saw and the bone window was formed.

When the dura was opened, the posterior part of frontal lobe, the Sylvian fissure and anterior part of temporal lobe were exposed. The anterior part of temporal lobe was dissected along the Sylvian fissure and retracted backward to reduce the occlusion. Then the supra-tentorial structures in middle cranial fossa, especially located in the parasellar region and cavernous sinus, such as the oculomotor nerve, clinoid process superior portion of the internal carotid artery and posterior cerebral artery bypass above the tentorium, appeared in the microscope. Furthermore, we kept on exposing the infra-tentorial part of middle cranial fossa by dissecting the tentorium which was located anterior to the petrous bone. With the adjustment of the visual angle, the posterior cranial fossa structures located upper to the level of middle and upper clivus would be seen in the microscope. The free, cut edge of the tentorium was enlarged according to tumor size and position. The observable structures were photographed and the length of specified segment of correlative cranial nerves was measured (Table I).

\section{Comparison of the Percentage of Projected Area}

The real areas of the anterior triangle $A M L$ and posterior triangle PML were calculated from all 10 sides of 5 cadaveric heads. Then, the projected areas of the anterior and posterior triangles in both bone window planes of the EPTT approach and ST approach were calculated by Microsoft visual $\mathrm{C}++6.0$ 
Table I: The Distances of Partial Specified Segments of Cranial Nerves to Bony Structures in Petroclival Region ( $n=10)$

\begin{tabular}{l|l|l|c|}
\hline Cranial nerves & Initiation site & Destination site & Length (mm) \\
\hline Oculomotor nerve & Run through PCA and SCA & Run into the superior wall of cavernous sinus & $20.62 \pm 3.18$ \\
\hline Trochlear nerve & Petrous apex & Run into the tentorium & $4.42 \pm 0.86$ \\
\hline Trigeminal nerve & Petrous apex & Run into the Meckel's cave & $11.92 \pm 1.36$
\end{tabular}

Table II: The Real and Projected Areas of the Anterior and Posterior Triangles in Both the EPTT and ST Approaches ( $\mathrm{n}=10$ )

\begin{tabular}{|l|c|c|c|}
\hline Triangle & Real area $\left(\mathrm{mm}^{2}\right)$ & $\begin{array}{c}\text { Projected area in the } \\
\text { EPT approach }\left(\mathrm{mm}^{2}\right)\end{array}$ & $\begin{array}{c}\text { Projected area in the ST } \\
\text { approach }\left(\mathrm{mm}^{2}\right)\end{array}$ \\
\hline Anterior triangle (AML) & $274.7 \pm 47.8$ & $56.0 \pm 28.9$ & $73.8 \pm 34.3$ \\
\hline Posterior triangle (PML) & $616.3 \pm 87.1$ & $455.6 \pm 66.0$ & $316.5 \pm 45.4$ \\
\hline
\end{tabular}

Table III: Comparison of the Percentage of the Projected Area of Anterior and Posterior Triangles in both the EPTT and ST Approaches $(\mathrm{n}=10)$

\begin{tabular}{|l|c|c|c|}
\hline $\begin{array}{l}\text { Percentage } \\
\text { of Projected area (\%) }\end{array}$ & EPTT approach (\%) & ST approach (\%) & value \\
\hline $\begin{array}{l}\text { Anterior triangle (AML) } \\
\text { Posterior triangle (PML) }\end{array}$ & $21.5 \pm 12.5$ & $28.8 \pm 14.9$ & 0.1948 \\
\hline
\end{tabular}

(Table II). The percentage of the projected area, which was converted by comparing the projected area with the real area, was used to perform the paired t test. The result showed that there was no statistical difference in the percentage of projected area of the anterior triangle $\mathrm{AML}$ for the two approaches (EPTT, $21.5 \pm 12.5 \%$; ST, $28.8 \pm 14.9 \% ; p=0.1948$ ). However, it is remarkable that the percentages of projected area of the posterior triangle PML for the two approaches (EPTT, $74.0 \pm 4.5 \%$; ST, $51.5 \pm 4.3 \% ; \mathrm{p}<0.01$ ) show a statistically significant difference (Table III).

\section{DISCUSSION}

\section{Development of Petroclival Approaches}

The development of petroclival approaches has undergone 4 periods. In early 1950s, little information about the petroclival region could be obtained owning to the lacking iconography technique. Therefore, this region was considered as the "restricted zone" in neurosurgical procedures (6). Soon after, a few experts tried limited removal of the petroclival lesions basis of the skull base anatomy (18). But the postoperative outcomes were not as desired. With the 1980s and rapid development of neurosurgical microtechnique, the HorsleyClarke technique and adjunctive image technology, more and more surgical approaches were developed to manipulate petroclival lesions. This period was the "golden time" of neurosurgical development (4). The concept of "More-thanless" regarding tumor removal was accepted by majority of neurosurgeons. However, the morbidity and mortality was not satisfactory in spite of many patients with total tumor resection $(9,14)$. The postoperative complications, including neurological deficits and vascular damages, were still serious and hard to avoid. After the $21^{\text {st }}$ century, the neurosurgeons started to pay more attention to the protection of the blood vessels and cranial nerves. The surgical concept "Less-thancomplete" has been advocated and promoted. Total removal has been not the primary consideration during the surgical treatment of petroclival tumors. This change of the concept has improved the patients' postoperative quality of life (5, $15,25,27)$. Affected by this concept, petroclival approaches have been developed to provide a simple, minimal invasive procedure with maximum exposure.

laconetta subdivided the petroclival approaches into 4 types according to the craniotomy location: the anterior approaches, lateral approaches, posterior approaches and combined approaches (12). The anterior approaches include the orbital-zygomatic, fronto-temporo-orbito-zygomatic and pterional approach. The lateral approaches include the subtemporal, transpetrosal presigmoid and extended middle fossa approach $(8,28)$. The posterior approaches include the suboccipital retrosigmoid approach. The combined approaches include the combined supra- and infra-tentorial presigmoid, infratemporal and retrosigmoid combined approach. The neurosurgeons select an individual approach according to the petroclival tumor size, location and invasive direction $(2,4,5,10,21,25,26)$.

The transpetrosal presigmoid approach was commonly used for petroclival lesions previously. It can not only ensure larger exposure and shorter distance, but also provide remarkable assistance to reduce the retraction of the temporal lobe and preserves the integrity of Labbe's vein $(1,3,20,29)$. However, the disadvantages such as being time-consuming, the extensive destruction of the skull base, the high risk of neurological deficits and CSF leakage lead to slow recovery 
and a poor outcome. The suboccipital retrosigmoid approach was widely used to manipulate lesions in cerebellopontine angle and lower clivus $(7,23)$. However, tumor removal had to be performed through the interspace of VII-XII cranial nerves. It could lead to nerve damage easily and the posterior approach also has a disadvantage in the excision of the tumor parts in the upper clivus and middle cranial fossa. The neurosurgeon should therefore choose a compatible approach for dealing with the petroclival lesions without damaging other important structures.

\section{The Anatomic Characters and Applicability of the EPTT and ST Approaches}

The extended pterional transtemporal transtentorium approach, as one of the variants of pterional approach, has 3 key points: first, "extended pterional" means that the skin incision has a backward enlargement to increase the exposure of the temporal lobe; second, "transtemporal" means that the anterior part of temporal lobe was dissected along the direction of the Sylvian fissure and retracted backward to expose supra-tentorium structures in middle cranial fossa after craniotomy and dura dissection; third, "transtentorium" means that the tentorium was dissected extensively to expose the infra-tentorium structures in the middle cranial fossa and posterior cranial fossa.

The tentorium dissection was started from the segment in front of the petrous bone to expose the infra-tentorium structures in the middle cranial fossa and manipulate the tumor in this region. Then, the visual angle of surgeon was adjusted to the rear, the segment of tentorium behind the petrous bone was dissected and the remaining lesion in the posterior cranial fossa was exposed and finally removed. In the entire tentorium dissection process, much attention should be paid to the passing cranial nerves and blood vessels, such as the oculomotor nerve, trochlear nerve, trigeminal nerve, abducens nerve, posterior cerebral artery, superior cerebellar artery, superior petrosal sinus and so on. Above all, the trochlear nerve bypasses the cerebral peduncle of the midbrain through the oculomotor triangle into the superior wall of cavernous sinus. Its travel is very close to the inner free margin of tentorium and the trochlear nerve is therefore easily injured during tentorium dissection.

The statistical results showed that with regard to exposed area in anterior triangle the EPTT approach provided nearly equivalent percentages of projected areas compared with the ST approach and these two approaches have no significant difference $(p=0.1948)$. This means that when neurosurgeons manipulate the petroclival tumors that are predominantly in the middle cranial fossa, these two approaches could provide similar exposure. However, this situation changed in the petroclival tumor predominantly in the posterior triangle. The EPTT approach has a bigger percentage of projected area than the ST approach $(p<0.01)$. This means that when treating a petroclival tumor predominantly in posterior cranial fossa, the EPTT approach could provide a wider operative area. As we all know, neurosurgeons prefer a more exposed approach such as EPTT rather than ST. Moreover, compared with the lateral approach, it is not easy to injure Labbe's vein with the anterior approach.

There are obviously some deficiencies of both approaches. In the ST approach, the preservation of Labbe's vein and the extent of retraction to the temporal lobe are tremendous problems for the surgeon $(15,19)$. Moreover, because of the occlusion of petrous bone, the exposure of the posterior cranial fossa is unsatisfactory in the ST approach (30). In spite of experimental statistical data confirming that the surgical exposure of the posterior cranial fossa is significant better in the EPTT approach, the petrous bone still prevents the surgeon from observing the cerebellopontine angle and lower clivus. The brainstem section that could be clearly exposed was the lateral inferior segment of the midbrain and the whole pons. Besides, the EPTT approach has a longer surgical distance to the petroclival region than the ST approach, especially when used to manipulate posterior petroclival lesions. That is to say, while the EPTT approach improved the operating angle to enlarge the exposed area in the posterior cranial fossa, at the same time it increased the surgical distance versus the ST approach. This indicates that if you want to select the EPTT approach to remove petroclival tumors as a surgeon, you must be skillful at micromanipulation and use exact judgement to handle tumors at a relatively long distance.

In conclusion, the extended pterional transtemporal transtentorial (EPTT) approach and the subtemporal transtentorial (ST) approach are all suitable for the petroclival tumors that are predominantly in the middle cranial fossa. Moreover, the extended pterional transtemporal transtentorial approach is also beneficial for large and giant petroclival tumors predominantly in the posterior cranial fossa with extensive invasion to the parasellar structures and cavernous sinus.

\section{Study Limitations}

This study still has several limitations. First of all, formalinfixed cadaveric tissue can not simulate many characteristics of living tissue completely. The cadaveric tissue has much more rigidity than living tissue, so there may be some differences in the stretching of temporal tissue when the EPTT approach is applied clinically. We will continue to conduct further relevant clinical research. Nonetheless, this quantitative anatomic study can help surgeons find the appropriate approach by utilizing the information about the comparative advantages of various approaches to the petroclival region.

\section{REFERENCES}

1. Ammirati $M$, Samii $M$ : Presigmoid sinus approach to petroclival meningiomas. Skull Base Surg 2: 124-128, 1992

2. Bambakidis NC, Kakarla UK, Kim LJ, Nakaji P, Porter RW, Daspit CP, Spetzler RF: Evolution of surgical approaches in the treatment of petroclival meningiomas: $A$ retrospective review. Neurosurgery 61: 202-209; discussion 209-211, 2007 
3. Behari S, Tyagi I, Banerji D, Kumar V, Jaiswal AK, Phadke RV, Jain VK: Postauricular, transpetrous, presigmoid approach for extensive skull base tumors in the petroclival region: The successes and the travails. Acta Neurochir (Wien) 152:16331645,2010

4. Bricolo AP, Turazzi S, Talacchi A and Cristofori L: Microsurgical removal of petroclival meningiomas: A report of 33 patients. Neurosurgery 31: 813-828; discussion 828, 1992

5. Calbucci F: Treatment strategy for sphenopetroclival meningiomas. World Neurosurg 75: 419-420, 2011

6. Castellano F, Ruggiero G: Meningiomas of the posterior fossa. G Ital Chir 9: 71-78, 1953

7. Chen LF, Yu XG, Bu B, Xu BN, Zhou DB: The retrosigmoid approach to petroclival meningioma surgery. J Clin Neurosci 18: 1656-1661, 2011

8. Danner C, Cueva RA: Extended middle fossa approach to the petroclival junction and anterior cerebellopontine angle. Otol Neurotol 25: 762-768, 2004

9. DeMonte F, Smith HK and al-Mefty O: Outcome of aggressive removal of cavernous sinus meningiomas. J Neurosurg 81: 245-251, 1994

10. Erkmen K, Pravdenkova S, Al-Mefty O: Surgical management of petroclival meningiomas: factors determining the choice of approach. Neurosurg Focus 19: E7, 2005

11. Fournier HD, Mercier $P$, Roche $P H$ : Surgical anatomy of the petrous apex and petroclival region. Adv Tech Stand Neurosurg 32: 91-146, 2007

12. laconetta G, Fusco M, Samii M: The sphenopetroclival venous gulf: A microanatomical study. J Neurosurg 99: 366-375, 2003

13. Jittapiromsak P, Deshmukh P, Nakaji P, Spetzler RF, Preul MC: Comparative analysis of posterior approaches to the medial temporal region: Supracerebellar transtentorial versus occipital transtentorial. Neurosurgery 64: 35-42; discussion 42-43, 2009

14. Kawase T: Advantages and disadvantages of surgical approaches to petroclival lesions. World Neurosurg 75: 421, 2011

15. Kawase T, Shiobara R, Toya S: Anterior transpetrosaltranstentorial approach for sphenopetroclival meningiomas: Surgical method and results in 10 patients. Neurosurgery 28: 869-875; discussion 875-876, 1991

16. Krayenbuhl HA, Yasargil MG, Flamm ES, Tew JM Jr: Microsurgical treatment of intracranial saccular aneurysms. J Neurosurg 37: 678-686, 1972

17. Laurent $C P$, Jolivet $E$, Hodel J, Decq $P$, Skalli W: New method for $3 D$ reconstruction of the human cranial vault from CTscan data. Med Eng Phys 33: 1270-1275, 2011
18. Ledinski G: Proceedings: Experience with meningiomas in the posterior fossa. Acta Neurochir (Wien) 31: 284-285, 1975

19. Lin H, Zhao G: A comparative anatomic study of a modified temporal-occipital transtentori nspetrosal-ridge approach and a transpetrosal presigmoid approach. World Neurosurg 75: 495-502, 2011

20. Mandelli C, Porras L, Lopez-Sanchez C, Sicuri GM, Lomonaco I, Garcia-Martinez V: The partial labyrinthectomy petrous apicectomy approach to petroclival meningiomas. A quantitative anatomic comparison with other approaches to the same region. Neurocirugia (Astur) 19: 133-142, 2008

21. Mendenhall WM, Friedman WA, Amdur RJ, Foote KD: Management of benign skull base meningiomas: A review. Skull Base 14: 53-60; discussion 61, 2004

22. Ray B, Rajagopal KV, Rajesh T, Gayathri BM, D'Souza AS, Swarnashri JV, Saxena A: Morphometry and CT measurements of useful bony landmarks of skull base. Rom J Morphol Embryol 52: 873-877, 2011

23. Samii M, Tatagiba M and Carvalho GA: Retrosigmoid intradural suprameatal approach to Meckel's cave and the middle fossa: Surgical technique and outcome. J Neurosurg 92: 235-241, 2000

24. Scholz M, Parvin R, Thissen J, Lohnert C, Harders A, Blaeser K: Skull base approaches in neurosurgery. Head Neck Oncol 2: 16,2010

25. Seifert V: Clinical management of petroclival meningiomas and the eternal quest for preservation of quality of life: Personal experiences over a period of 20 years. Acta Neurochir (Wien) 152: 1099-1116, 2010

26. Stippler M, Kondziolka D: Skull base meningiomas: Is there a place for microsurgery. Acta Neurochir (Wien) 148: 1-3, 2006

27. Tahara A, de Santana PA Jr, Calfat MMV, Panagopoulos AT, da SAN, Zicarelli CA, de Aguiar PH P: Petroclival meningiomas: Surgical management and common complications. J Clin Neurosci 16: 655-659, 2009

28. Tedeschi H, Rhoton AL Jr: Lateral approaches to the petroclival region. Surg Neurol 41: 180-216, 1994

29. Wu CY, Lan Q: Quantification of the presigmoid transpetrosal keyhole approach to petroclival region. Chin Med J (Engl) 121: 740-744, 2008

30. Yang J, Ma SC, Fang T, Qi JF, Hu YS, Yu CJ: Subtemporal transpetrosal apex approach: Study on its use in large and giant petroclival meningiomas. Chin Med J (Engl) 124: 49-55, 2011

31. Yasargil MG, Antic J, Laciga R, Jain KK, Hodosh RM, Smith RD: Microsurgical pterional approach to aneurysms of the basilar bifurcation. Surg Neurol 6: 83-91, 1976 